\title{
Nano Synthesis and Characterization of Complex Derived from Silver Metal Conjugated with Midodrine Hydrochloride
}

\author{
NAMITA BHARADWAJ ${ }^{1}$ and JAISHRI KAUSHIK ${ }^{1 *}$ \\ Department of Chemistry, Dr. C.V. Raman University, Kota, Bilaspur, C.G., India. \\ ${ }^{*}$ Corresponding author E-mail: kaushik.jaishri08@gmail.com \\ http://dx.doi.org/10.13005/ojc/370121
}

(Received: January 22, 2021; Accepted: February 22, 2021)

\begin{abstract}
The stability constant $\mathrm{K}_{\mathrm{f}}$ for the complexation of $\mathrm{Ag}(\mathrm{I})$ metal ion with Midodrine hydrochloride were determined by spectrophotometric method at room temperature. The colored complexes were measured at $300 \mathrm{~nm}$. The stability constant of the complexes were found to be 5.47 by mole ratio method. The stoichiometry of the complexes formed between the Midodrine drug and $\mathrm{Ag}$ (I) metal ion are $1: 1 \mathrm{M} / \mathrm{L}$ ratio. Silver conjugated Midodrine hydrochloride Nano synthesized and characterized by UV-Visible spectroscopy, SEM, XRD and FT-IR. The UV-Visible spectra of Midodrine -Ag nanoparticle in the range of $322 \mathrm{~nm}$. XRD conform The crystallite size of Midodrine - $\mathrm{Ag}$ (I) nanoparticles are found to be $64.5 \mathrm{~nm}$ from Debye Scherer formula. The crystallinity of nanoparticles is Face centered cubic structure. SEM conform of particle size and surface morphology, FTIR analyzed involvement of $-\mathrm{NH}_{2}$ group in Midodrine is the stabilized of silver nanoparticle. This research is focuses on complexation, Nano synthesis and characterization of Drug-silver nanoparticle for antihypotention therapy.
\end{abstract}

Keywords: Complexation, Antihypotensive drug, Nano synthesis, XRD, SEM, FT-IR.

INTRODUCTION

One of the antihypotensive drugs, midodrine hydrochloride chemical name 2-amino- $\mathrm{N}-[2-(2$, 5-dimethoxyphenyl) hydroxyethyl] acetamide; hydrochloride and chemical formula is $\mathrm{C}_{12} \mathrm{H}_{19} \mathrm{CIN}_{2} \mathrm{O}_{4}{ }^{1}$ which is used for the treatment of low blood pressure that upgrade the blood pressure. That drug involves the shrinking of blood vessels and elevated blood pressure $^{2}$. The interaction of antihypotensive drug Midrodrine with $\mathrm{Ag}(\mathrm{I})$ ion lead to formation of complexes. Nanotechnology representation, one of the great breaks through of warrant matter which is formed thought the different composition of material size and structure. Nano material is distributed based on their size 1-100 $\mathrm{nm}$. That nanoparticle or nanomaterial are seen decomposition or reduced at atomic and polymer material and they show different chemical, physical and spectral properties. Preparations of nanoparticle are need to their utilization and this remains a field of active research ${ }^{3}$ where drug is dissolved, entrapped, encapsulated or attached to a nanoparticle matrix.

Nano capsules are system in which were Midodrine is cramped to a cavity of silver metal ion and that metal ion is surrounded by ligand Midodrine $^{4}$. Inorganic nanomaterials have attracted

This is an Open Access article licensed under a Creative Commons license: Attribution 4.0 International (CC- BY). Published by Oriental Scientific Publishing Company @ 2018

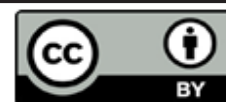


much attention as drug carriers due to their excellent biocompatibility, bioactivity, and lack of susceptibility towards immune system ${ }^{5}$.

Nanoparticle-based drug delivery systems have been developed and that show several advantages like improved solubility of drug in serum, increased half-life of drug in body, controlled and targeted drug release, currently these systems have now been employed for combination therapy using multiple drugs targeting identical cells $s^{6}$ In field of Nano medicines there are many merits, the magnification of drug absorption into tissues, refinement of their mode of action, and developments of intracellular tissues ${ }^{7,8}$. Due to their different physicochemical property like optical, electronic and magnetic property drug -Ag Nps has been studied extensively9.

\section{MATERIALS AND METHODOLOGY}

Instrumentation-Systronic UV-Visible double beam spectrophotometer type 118 and $1 \mathrm{~cm}$ quartz cell were used for the absorption spectra. Sartorius BSA224S-CW electronic chemical balances are used for accurately weight of chemical. Systronic $\mathrm{pH}$ system 361 is a high performance $\mathrm{pH}$ meter is used for adjusting $\mathrm{pH}$ of buffer solution and complexes.

\section{Reagents}

All chemical were used of analytical grade. Drug Midodrine hydrochloride purchased from TCl chemical Pvt Ltd (India). Analytical grade nitrate salt of silver and phosphate buffer purchased from Merck. Sodium borohydrate and sodium citrate from merck. For all working solution deionized water is used.

\section{Preparation of standard Stock solution}

Midodrine hydrochloride $\left(1 \times 10^{-2} \mathrm{M}\right)$ is prepared by $1.27 \mathrm{~g}$ dissolved in deionized water and makeup up to $100 \mathrm{ml}$ volumetric flask ${ }^{10}$. Metal stock solution is prepared by dissolving Silver nitrate (M.W.$169.8,0.1 \mathrm{M} 0.849 \mathrm{~g}$ ) dissolved in deionized water and then makeup to the mark in $100 \mathrm{~mL}$ volumetric flask. Sodium borohydrate $5 \mathrm{mM}$, M.W. 37.83 is freshly prepared by dissolving $0.189 \mathrm{~g}$ in deionized water and make up into $100 \mathrm{ml}$ volumetric flask.
Complexation of midodrine hydrochloride with $\mathrm{Ag}$ (I) metal ion

A series of solution mixtures are prepared with a variable concentration of Midodrine and constant Ag (I) Metal ion in $\mathrm{mL}$. Midodrine solution varying from $0.5 \mathrm{~mL}-3.5 \mathrm{~mL}$ and $1.0 \mathrm{~mL}$ of silver nitrate solution added each solution of midodrine. Added $4 \mathrm{~mL}$ of buffer solution and makeup up to 10 $\mathrm{mL}$ measuring flask with deionized water. Mixtures are allowed to stand 20 minute. Blank solution is prepared by midodrine drug and deionized water. The higher absorbance of blank solution is standard value of wavelength. And this wavelength are selected for analysis the absorbance of series solution. The absorption spectra of these mixtures were recorded at $35^{\circ} \mathrm{C}$. The analysis is reported in tabulated and graphical form.

\section{Determination of Stability Constant by mole ratio method-}

Stoichiometric of complexes formed in the solution determined by spectrophotometric applying mole ratio method ${ }^{12}$. The logarithmic constant $\left(\log K_{f}\right)$ and the free energy change $\Delta G$ of form complexes are calculated from the data of mole ratio method applying equation $1 \& 2$. The equation for mole ratio method is

$$
\begin{aligned}
& \mathrm{K}_{\mathrm{f}}=\mathrm{A} / \varepsilon_{\mathrm{b}} /\left[\mathrm{CM}-\mathrm{A} / \varepsilon_{\mathrm{b}}\right] \times\left[\mathrm{CL}-\mathrm{A} / \varepsilon_{\mathrm{b}}\right] \\
& \Delta \mathrm{G}=-2.303 \mathrm{RT} \log \mathrm{K}_{\mathrm{f}}
\end{aligned}
$$

Were $\varepsilon_{\mathrm{b}}=$ molar absorptivity, $\mathrm{A}=$ absorbance at peak point, $\mathrm{CM}=$ concentration of metal, $\mathrm{C}_{\mathrm{L}}=$ concentration of ligand, $T$ is the absolute temperature and $\mathrm{R}$ is the gas Constant.

\section{Synthesis of Midodrine conjugated Ag Nps}

Midodrine -Ag Nps are synthesized. 10 $\mathrm{mL}\left(1 \times 10^{-2} \mathrm{M}\right)$ of Midodrine solution added in 10 $\mathrm{mL}\left(1 \times 10^{-1} \mathrm{M}\right) \mathrm{AgNo}^{3}$. This solution mixture is magnetically stirred for 15 minute. After that $\mathrm{NaBH}_{4}$ which is freshly prepared added $25 \mathrm{ml}\left(5 \times 10^{-3} \mathrm{M}\right)$ drop wise in the reaction mixture. Suddenly reaction mixture solution colour turned transparent to dirty Brown, Centrifuged Nanoparticle at 5,000 $\times \mathrm{g}$ for $8 \mathrm{~h}$ supernatant particles was dried at $50^{\circ} \mathrm{C}$ and collected the nanoparticle sample.

\section{Characterization of Drug -Ag conjugated Nps}

The prepared nano conjugated midodrine- 
$\mathrm{Ag}(\mathrm{I}) \mathrm{Nps}$ characterized by several analytical techniques and the obtained data is analyzed. Visible spectroscopy gives the absorption and optical properties of the prepared nanoparticle. X-ray diffraction patterns gives the crystalline structure, SEM was used to monitor the size and shape FT-IR reveals the presence of functional group bond and other bonds in the sample. The results obtained from the above investigations are analyzed for confirming the nanoparticle of drug conjugated $\mathrm{Ag}$ (I) nanoparticle ${ }^{13}$.

\section{RESULT AND DISCUSSION}

Table 1: Spectrophotometric experimental data for complexation of midrodrine $-\mathrm{Ag}(\mathrm{I})$ by mole ratio method

\begin{tabular}{|c|c|c|}
\hline $\begin{array}{l}\text { Meta lion concentration } \\
\quad 1 \times 10^{-1} \mathrm{~mol}(\mathrm{~mL})\end{array}$ & $\begin{array}{l}\text { Ligand concentration } \\
\qquad 1 \times 10^{-2} \mathrm{~mol}(\mathrm{~mL})\end{array}$ & $\begin{array}{l}\text { O.D at } \\
300 \mathrm{~nm}\end{array}$ \\
\hline 0.5 & 1 & 2.826 \\
\hline 1 & 1 & 3.014 \\
\hline 1.5 & 1 & 2.928 \\
\hline 2 & 1 & 2.883 \\
\hline 2.5 & 1 & 2.97 \\
\hline 3 & 1 & 2.983 \\
\hline 3.5 & 1 & 2.99 \\
\hline \multirow{2}{*}{\multicolumn{3}{|c|}{$\begin{array}{l}\text { absorbance of midodrine-Ag( I ) } \\
\text { metalion }\end{array}$}} \\
\hline & & \\
\hline 0 & 3 & \\
\hline
\end{tabular}

Fig. 1. Absorbance vs. concentration plot for midodrine hydrochloride with $\mathrm{Ag}$ (I) complex

When the ligand solutions are mixed with metal ions solution it is observed colour of solution was changed above the $9.2 \mathrm{pH}$. That indicates the complex formation between metal ion and ligand. The stability constant $\mathrm{K}_{\mathrm{f}}$ of Midodrine complex with $\mathrm{Ag}(\mathrm{I})$ metal ions determined by spectrophotometrically mole ratio method. The UV-Visible spectrum for Midodrine $-\mathrm{Ag}(\mathrm{I})$ complexes reveal maximum absorbance at $300 \mathrm{~nm}$. The stability constant for Midodrine -Ag(I) complex found to be 5.47 and free gib's energy is calculated to be in negative value 4.30. It's successfully demonstrated that the binding ability of midodrine hydrochloride along with silver metal ion by spectrophotometry technique.

\section{UV-Visible spectroscopy-}

The Nanoparticle formation can easily be monitored through its distinctive color change. Within the first minute of sodium borohydride injected with drug - $\mathrm{Ag}(\mathrm{I})$ complex. The solution became light brown ${ }^{14}$. Addition of $\mathrm{NaBH}_{4}$ is indicate reduction of $\mathrm{Ag}(\mathrm{I})$ metal ion and the formation of Midodrine -Ag NPs ${ }^{15}$. Drug-Ag(I) NPs are preparatory characterized by using UV-Visible double beam spectrophotometer.

UV-Spectrophotometric analysis of Drug$\mathrm{Ag}(\mathrm{I})$ complex are monitored from $200 \mathrm{~nm}$ to 800 $\mathrm{nm}$, and a strong peak specific to synthesized nanoparticle are observed at $322 \mathrm{~nm}$ Fig. 2. The ratio of optimization rated to be $1: 1$ for midodrine and $\mathrm{Ag}(\mathrm{I})$ metal ion. The optimizing ratio at which maximum absorbance of UV-Vis spectrum found, considered as Midodrine-Ag(I) nanoparticles are synthesized. UV-Vis spectra of Midodrine conjugated $\mathrm{Ag}(\mathrm{I})$ nanoparticles appear a sharp peak at $322 \mathrm{~nm}$.

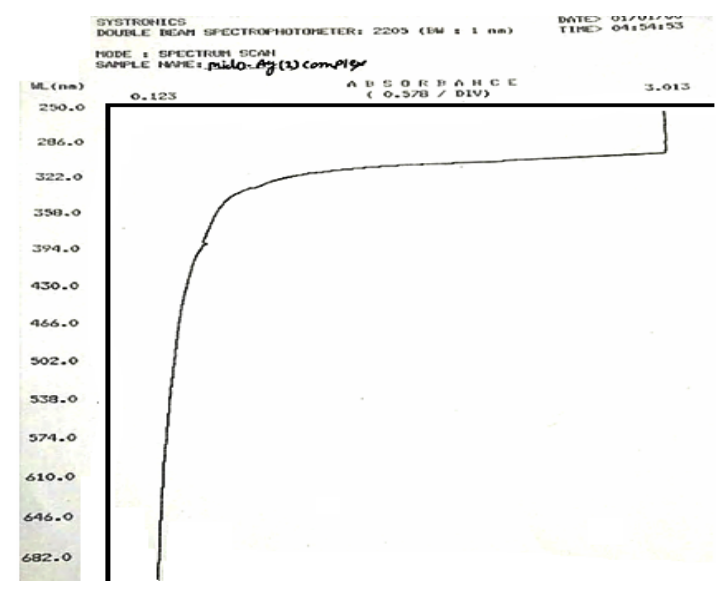

Fig. 2. UV-Visible spectra analysis of Midodrine-Ag (I) conjugated nanoparticle

\section{X-ray diffraction (XRD) analysis}

$X$-ray diffraction is the most important techniques to acknowledge analyzed structural properties of synthesized NPs. It gives adequate information about the crystallinity and plane of $\mathrm{NPs}^{16}$. That techniques functioning well for both single and multiphase nanoparticle identification ${ }^{17}$. The X-ray diffraction (XRD) patterns of prepared Midodrine conjugated $\mathrm{Ag}(\mathrm{I})$ nanoparticles identified by using $\mathrm{X}$-ray diffractometer along CuK $\alpha$ radiation $(\lambda=$ $1.5406 \AA$ ) is shown in Figure 3. 


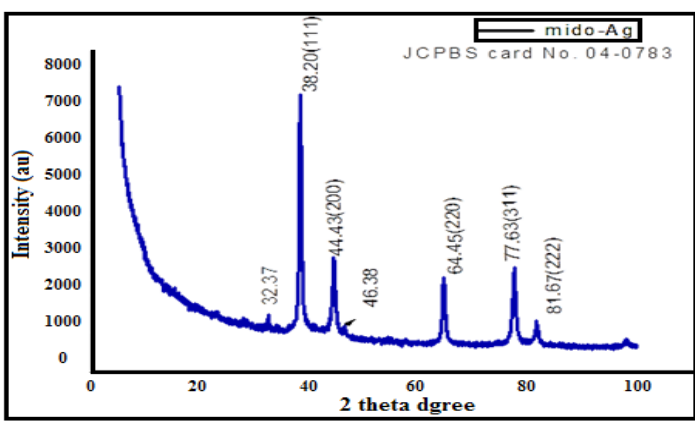

Fig. 3. XRD Pattern recorded from Midodrine-Ag(I) Nanoparticle

The intense peaks at $2 \theta$ values of Midodrine-Ag(I) $38.200,44.43^{\circ}, 64.45^{\circ}, 77.630$, 81.670. Corresponds to the planes of (111), (200), (220), (311), (222). 32.37, 46.38 respectively. In addition to these peaks, possibly due to organic compound crystal present in the sample conforms the $\mathrm{Ag}(\mathrm{I})$ nanoparticles matching with JCPDS Card No. 04-0783. The crystalline size of midodrine$\mathrm{Ag}(\mathrm{I})$ nanoparticles was found to be $64.5 \mathrm{~nm}$ \& from Debye Scherer formula. It is observed that the crystal structure of silver nanoparticles is FCC (Face centered cubic) based on the above planes (111), (200), (220), (311), (222). The diffractogram pattern conforms highly crystalline nature of synthesized materials as Midodrine-Ag (I) nanoparticles.

\section{Scanning Electron Microscopy (SEM)}

Scanning electron microscopy is used for the analysis of particle shape and morphology of microelement/trace element nanoparticles and also conjugated nanomaterial ${ }^{18}$. For analysis of SEM, fine powder of Midodrine -Ag NPs are used. SEM images of conjugated Drug-Ag nanoparticles are recorded by JSM-6510LV scanning electron microscope (JEOL, Tokyo, Japan) operated at speed up voltage of $30 \mathrm{kV}$. For SEM image, a pinch of synthesized Midodrine-Ag(I) nanoparticles are placed on carbon coated grid at potential set off 110 $\mathrm{KeV}$. Average particles size of drug conjugated Ag (I) nanoparticles is $64 \mathrm{~nm}$.

Figure 4 represents the SEM micrographs of Midodrine - $\mathrm{Ag}(\mathrm{I})$ Nanoparticles observed at different magnifications. The SEM images represent the agglomeration of particles. It is also be seen that the samples synthesized were Nano flakes which were turned to the particles when observed at different magnification.

\section{FTIR Analysis}

FTIR technique is helpful for the identification of ligand functionalities which is responsible for

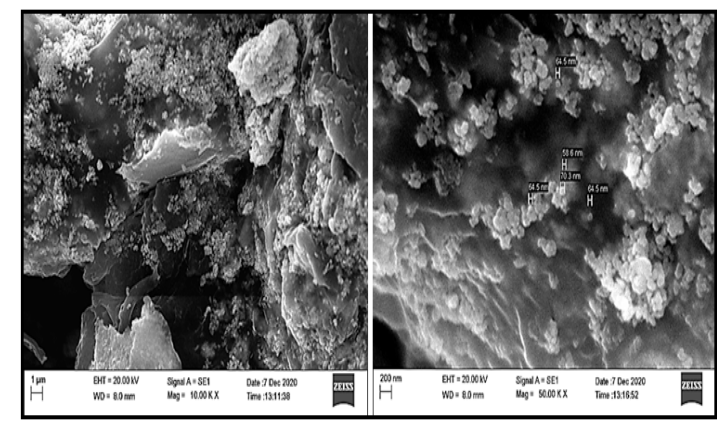

Fig. 4. SEM image of Mido-Ag(I) Nanoparticle observed at different magnification

stability of nanoparticle. It is well reported that drug functional group were involve in capping agent the synthesis drug conjugated with Ag Nanoparticle and it is analyzed by FTIR with the help of this enable to recognize which functional group involved in Midodrine-Ag Nps nano-synthesis.

The FTIR spectrum of midodrine hydrochloride/Ag nano particle revealed the present of absorption peak at $3741 \mathrm{~cm}^{-1} 2887 \mathrm{~cm}^{-1}$ for $\mathrm{C}-\mathrm{H}$ starching frequency furthermore the presence of $1630 \mathrm{~cm}^{-1}$ and $1530 \mathrm{~cm}^{-1}$ peaks was associated for $\mathrm{C}=\mathrm{C}$ and amide bonding of organic ligand and the slightly broad peak of $1317 \mathrm{~cm}^{-1}-\mathrm{N}-\mathrm{C}$ stretching of ligand and $1150 \mathrm{~cm}^{-1} \mathrm{C}-\mathrm{O}$ stretching $662 \mathrm{~cm}^{-1}$ is for carbon halogen bond group (Fig. 5) and the high intensity peak of $1000 \mathrm{~cm}^{-1}$ is significant peak of $\mathrm{Ag}$. From the IR data all functionalities of Midodrine were involved and intense peak of Ag conform the Nano synthesis of our complex. Mido-Ag Nps. prefers to bind primary $\mathrm{NH}_{2}$ group. We can conclude that the organic ligand is successfully binded with Ag metal ion.

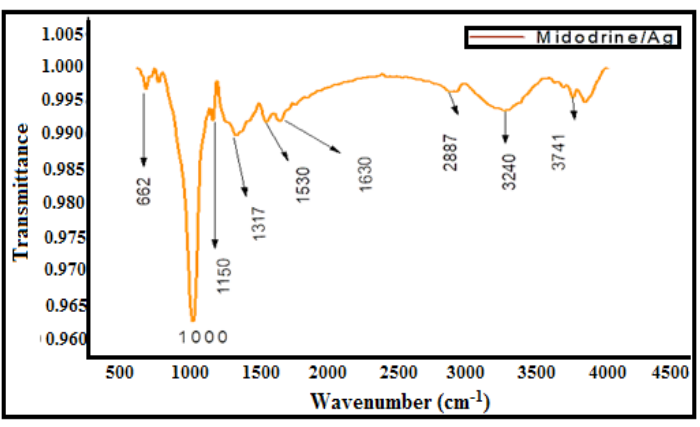

Fig. 5. FTIR spectrum of Midodrine -Ag Nps

\section{CONCLUSION}

The complexation of drug Midodrine hydrochloride and metal ion developed a new metal based drug, which could act against human hypotension. The work is successfully demonstrated that the use of UV-Visible spectroscopy is feasible 
in complexation reaction and stability constant. It was found that Drug and metal forms stable 1:1 $(\mathrm{M} / \mathrm{L})$ ratio of complexes. In new drug, based metal ion complexes, silver nanoparticle have many properties which demonstrate their potential use in hypotension therapy and that is easily synthesized by using chemical reduction agent such as sodium borohydride using standard procedure.

This complex is successfully Nano synthesized, characterized and conformed by UV-Visible spectroscopy, XRD, SEM, FTIR. Silver Nano synthesized drug represent a research field of increasing progress of pharmaceutical profile like biological activity of drugs, development of modified drugs, Decreases dosage of drugs. Antihypotensive drug as a chelating agents can be used for analysis of trace element ion.

\section{ACKNOWLEDGEMENT}

The authors are grateful to Dr. C.V. Raman University for their valuable support. The authors also like to give special thanks to metallurgy department of NIT Raipur and Pt. Ravi Shankar Shukla University Raipur for assistance in instruments analysis.

\section{Conflicts of interest} of interest.

Authors declare that they have no conflicts

\section{REFERENCE}

1. Jain, H.K.; Gujar, K.; Randhe, V.; Stability indicating RP-HPLC assay method for estimation of Midrodrine hydrochloride in bulk and tablet., J. of pharm pharma. sci., 2016, 8(9), 283-287.

2. Krishna, A.; Kavitha, M.P. ; Krishnakumar, K.; A review on the determination of Midrodrine hydrochloride in bulk and marked formulation by using different analytical techniques., World J. of Pharma. Res., 2013, 7(14), 260-266.

3. Khan, A.; Rashid, R.; Murtaza, G.; Zahra, A.; Gold nanoparticle: Synthesis and application in drug delivery., Tropical journal of Pharma Research., 2014, 13(7), 1169-1177.

4. Nagavarma, B.; Yadav, H.; Ayaz, A.; Shivakumar, H.; Different techniques for preparation of polymeric nanoparticles., Asian Journal Pharm., 2012, 5, 16-24.

5. Grace, J.L.; Elliott, A.G.; Huang, J.X.; Schneider, E.K.; Truong, N.P.; Cooper, M.A.; Li, J.; Davis, T.P.; Quinn, J.F.; Velkov, T.; Cationic acrylate oligomers comprising amino acid mimic moieties demonstrate improved antibacterial killing efficiency., J. Mater. Chem. B., 2017, 5, 531-536.

6. Alexis, F.; Pridgen, E.; Molnar, LK.; Farokhzad, O.c.; Factors affecting the clearance and bio distribution of polymeric nanoparticles., $\mathrm{Mol}$ Pharm., 2008, 5, 505-515.

7. Girdhar, V.; Patil, S.; Banerjee, S.; Singhvi, G.; Nano carriers for drug delivery: mini review., Curr Nanomed., 2018, 8, 88-99.

8. Anwar, A.; Khalid, S.; Perveen, S.; Ahmed, S.; Siddiqui, R.; Synthesis of 4-(dimethylamino) pyridine propylthioacetate coated gold nanoparticles and their antibacterial and photophysical activity., J. Nanobiotechnol., 2018, 16, 8-20.

9. Damle, M.C.; Salunke, S.; Stability-Indicating HPTLC method for determination of midodrine hydrochloride., Eur. J. of Phar and Medical Sci., 2016, 3(9), 202-207.

10. Bharadwaj, N.; Koshle, G.; Complexation of Norfloxacin with Some Transition Metal Ions -A Spectrophotometric Study., J Chem and Chem. Sci., 2016, 6(9), 821-825.

11. Issa, I.M.; Issa, R.M.; Ahmed, Y.Z.; The Th (IV), Ce(III) and U(VI) chelates with hydroxyanthraquinones., Egypt. J. Chem., 1975, 18, 427-438.

12. Devi, G.; Reddy, K.M.; Enhanced photocatalytic activity of silver metallized $\mathrm{TiO}_{2}$ particles in the Characterization and activity at different $\mathrm{pH}$ values., Applied Surface Science Elsevier., 2010, 265, 3116-3121.

13. Dhote, V.; Jain, P.; Jain, V.; New analytical method development and validation for the estimation of Midodrine $\mathrm{HCl}$ by UV and HPLC., Int. J. Res. Dev. Pharm., 2018, 7(4), 3060-3070.

14. Ahmed, D.; Shah, M.R.; Perveen, S.; Ahmed, S.; Cephradine Coated Silver Nanoparticle their Drug Release Mechanism, and Antimicrobial Potential against GramPositive and Gram-Negative Bacterial Strains through AFM., J. Chem. Soc. Pakistan., 2018, 40, 388-398.

15. Khan, I.; Abdalla, A.; Qurashi, A.; Synthesis of hierarchical WO3 and $\mathrm{Bi} 2 \mathrm{O} 3 / \mathrm{WO} 3$ Nano composite for solar-driven water splitting applications., Int. J. Hydro Energy., 2017, 42, 3431-3439.

16. Khan, I.; Saeed, K.; Khan, I.; Nanoparticles: Properties, applications and toxicities., Arabian Journal of Chemistry., 2019, 1(2), 2-12.

17. Rao, N.S.; Rao, V.B.; Structural and Optical Investigation of $\mathrm{ZnO}$ Nanopowders Synthesized from zinc chloride and zinc., American $J$ of Mater. Sci., 2015, 5(3), 66-68. degradation of an azo dye methyl orange: 